\title{
COMUNICAÇÃO
}

\section{AVALIAÇÃO DE CULTIVARES DE ARROZ DE TERRAS ALTAS SOB CONDIÇÕES DE SEQUEIRO EM CASSILÂNDIA, MS}

\author{
Upland field rice cultivars evaluation under rainfed condition in Cassilândia, MS \\ Eder Araújo da Silva ${ }^{1}$, Rogério Peres Soratto², Elisa Adriano ${ }^{1}$, Guilherme Augusto Biscaro ${ }^{3}$
}

\begin{abstract}
RESUMO
O uso de cultivares selecionadas é uma das tecnologias de mais fácil adoção pelo agricultor, pois além de incrementar a produtividade, é um dos insumos de menor custo na produção agrícola. Assim, é fundamental obter informações sobre o desempenho de novas cultivares, nas mais diversas regiões de cultivo. Objetivou-se, neste trabalho avaliar o comportamento de cultivares de arroz de terras altas (Oryza sativa L.) (BRS Aroma, BRS Bonança, BRS Colosso, BRSMG Conai, BRSMG Curinga, BRS Soberana, BRS Talento e IAC 202), sob condições de sequeiro, na região de Cassilândia, MS. O delineamento experimental foi o de blocos ao acaso, com quatro repetições. A semeadura foi realizada em 30 de novembro de 2005, no espaçamento de 0,40 m entre linhas e 70 sementes viáveis por metro. As cultivares BRS Talento, IAC 202 e BRS Soberana apresentaram comportamento superior. As cultivares BRS Soberana, BRS Bonança, BRS Colosso, IAC 202 e BRS Talento apresentaram maior rendimento de grãos inteiros. É possível obterse boa produtividade (acima de $3.000 \mathrm{~kg} \mathrm{ha}^{-1}$ ), na cultura do arroz de terras altas sob condições de sequeiro no município de Cassilândia, MS, desde que sejam utilizadas cultivares adequadas.
\end{abstract}

Termos para indexação: Oryza sativa, componentes da produção, qualidade de grãos.

\section{ABSTRACT}

The use of selected cultivars is one of the easiest technologies for adoption by the farmer; besides yield increase, it offers lower cost in the agricultural production. Thus, it is fundamental to obtain information about the performance of new cultivars, from the most diverse cropping regions. The purpose of this study was to evaluate the performance of the upland rice (Oryza sativa $\mathrm{L}$.) (BRS Aroma, BRS Bonança, BRS Colosso, BRSMG Conai, BRSMG Curinga, BRS Soberana, BRS Talento and IAC 202) under rainfed condition in Cassilândia, MS, Brazil. A randomized complete block design, with four replications was used. The seeds were sowed on November 30 2006, with $0.40 \mathrm{~m}$ between rows and a density of 70 viable seeds per meter. The results showed that BRS Talento, IAC 202, and BRS Soberana presented better performance. BRS Soberana, BRS Bonança, BRS Colosso, IAC 202, and BRS Talento presented larger whole grain yield. It is possible to obtain good rice grain yield higher than 3,000 $\mathrm{kg} \mathrm{ha}^{-1}$, under rainfed condition in Cassilândia, MS, since appropriate cultivars are used.

Index terms: Oryza sativa, yield components, grain quality.

(Recebido em 10 de agosto de 2007 e aprovado em 17 de janeiro de 2008)

O arroz (Oryza sativa L.) está entre os cereais mais importantes do mundo. No Brasil, assume papel de destaque por constituir fonte importante de calorias e de proteínas na dieta alimentar da população (FORNASIERI FILHO \& FORNASIERI, 2006).

O Brasil é o país que apresenta a maior área cultivada com arroz de terras altas (CRUSCIOL et al., 1999a), e a maior parte dessa área está concentrada no cerrado. Nessa região, o arroz, muitas vezes, é cultivado sob condição de sequeiro, em solos ácidos, pobres em nutrientes, com baixa capacidade de retenção de água e em regiões onde existe irregularidade na distribuição das precipitações pluviais, como é o caso da região de Cassilândia, no extremo nordeste do Estado de Mato Grosso do Sul, conhecida como Bolsão sul-mato-grossense. Além disso, a utilização de materiais não adaptados e práticas culturais inadequadas contribuem para que essa cultura apresente produção oscilante (CRUSCIOL et al., 1999b). Apesar de representar $65 \%$ da área cultivada, o arroz de terras altas responde por apenas $39 \%$ da produção nacional

\footnotetext{
'Engenheiro Agrônomo - Ex-aluno da Unidade Universitária de Cassilândia/UUC - Universidade Estadual de Mato Grosso do Sul/UEMS - Rodovia MS 306 Km 06 - 79540-000 - Cassilândia, MS - arasilvaeder@hotmail.com; elisaagrouems@hotmail.com

Engenheiro Agrônomo, Doutor, Professor Assistente - Departamento de Produção Vegetal - Faculdade de Ciências Agronômicas/FCA - Universidade Estadual Paulista/UNESP - Rua José Barbosa de Barros, 1780 - Campus de Botucatu - Cx. P. 237 - 18610-307 - Botucatu, SP - soratto@fca.unesp.br ${ }^{3}$ Engenheiro Agrícola, Doutor, Professor Adjunto - Faculdade de Ciências Agrárias/FCA - Universidade Federal da Grande Dourados/UFGD Rodovia Dourados-Itahum, Km 12 - Cx. P. 533 - 79804-970 - Dourados, MS - gbiscaro@ufgd.edu.br
} 
(FORNASIERI FILHO \& FORNASIERI, 2006; STONE et al., 2001).

Segundo Buzetti et al. (2006), a produtividade final da cultura do arroz depende da cultivar utilizada, da quantidade de insumos e das técnicas de manejo empregadas. $\mathrm{O}$ uso de cultivares melhoradas constitui a tecnologia de menor dispêndio para o produtor e, portanto, a de mais fácil adoção e que proporciona retornos econômicos em curto prazo (RANGEL et al., 2000). Além disso, a escolha da cultivar é uma das decisões determinantes do sucesso da lavoura de arroz, influenciando indiretamente todo o manejo a ser adotado (BRESEGHELLO et al., 1998). Assim, no momento de se escolher uma cultivar é necessário analisar suas características visando otimizar seu uso dentro da região e do sistema agrícola desejado (CASTRO et al., 2007).

A pesquisa tem desenvolvido novas cultivares de arroz, com maior resistência à seca, à brusone, ao acamamento com melhor qualidade de grãos e outros atributos agronômicos necessários a uma produtividade elevada e estável (BRESEGHELLO et al., 1998; FORNASIERI FILHO \& FORNASIERI, 2006). Contudo, a quantidade de cultivares de arroz de terras altas disponíveis no mercado tem sido considerada muito pequena, gerando poucas opções para os agricultores e aumentando o grau de risco, em conseqüência de amplas e contínuas áreas com uma única cultivar. Além disso, ainda são escassas as informações sobre o comportamento das cultivares lançadas recentemente, em cada região de cultivo.

Ojetivou-se, no trabalho avaliar o comportamento de diferentes cultivares de arroz de terras altas, sob condições de sequeiro na região de Cassilândia, MS.

$\mathrm{O}$ trabalho foi realizado na área experimental da Universidade Estadual de Mato Grosso do Sul, localizada no município de Cassilândia, MS ( $\left(51^{\circ} 48^{\prime} \mathrm{W}, 19^{\circ} 05^{\prime} \mathrm{S}, 507 \mathrm{~m}\right.$ de altitude), região do Bolsão Sul-mato-grossense, em área anteriormente cultivada com pastagem. O solo do local é Neossolo Quartzarênico (EMBRAPA, 1999), originalmente sob vegetação de cerrado, cujos resultados de análises química e granulométrica, da camada de $0-0,20 \mathrm{~m}$ de profundidade, foram: $\mathrm{pH}(\mathrm{CaCl} 2) 5,1 ; 10 \mathrm{mg} \mathrm{dm}^{-3}$ de $\mathrm{P}$ (resina); 1,6 $\mathrm{mmol}_{\mathrm{c}} \mathrm{dm}^{-3} \mathrm{de} \mathrm{K}$ trocável; $30 \mathrm{mmol}_{\mathrm{c}} \mathrm{dm}^{-3} \mathrm{de} \mathrm{Ca}$ trocável; $3 \mathrm{mmol}_{c} \mathrm{dm}^{-3} \mathrm{de} \mathrm{Mg}$ trocável; $26 \mathrm{mmol}_{c} \mathrm{dm}^{-3} \mathrm{de}$ $\mathrm{H}+\mathrm{Al}$; saturação por bases, $57 \% ; 23 \mathrm{~g} \mathrm{~kg}^{-1}$ de matéria orgânica; $877 \mathrm{~g} \mathrm{~kg}^{-1}$ de areia; $20 \mathrm{~g} \mathrm{~kg}^{-1}$ de silte; e $103 \mathrm{~g}$ $\mathrm{kg}^{-1}$ de argila.

Durante a realização do experimento foram registradas, diariamente, a temperatura mínima e máxima do ar e a precipitação pluvial no posto agrometeorológico da Universidade Estadual de Mato Grosso do Sul, Unidade de Cassilândia, ao lado da área experimental. Os dados são apresentados na Figura 1.

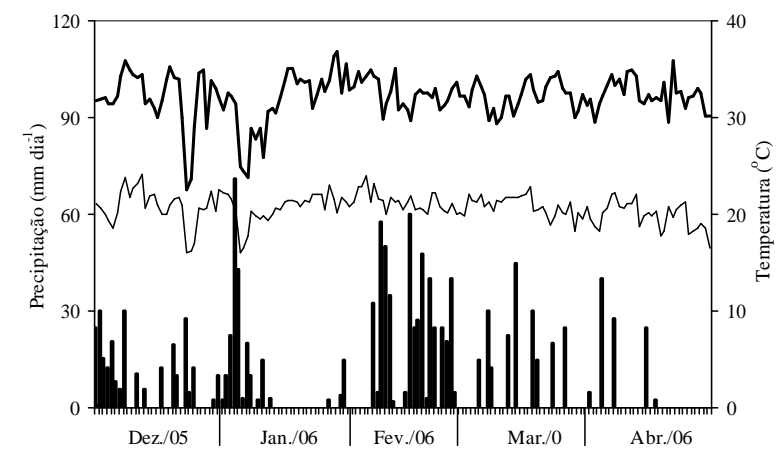

Figura 1 - Valores diários de precipitação pluvial (1 ), temperatura máxima (-) e mínima (- ) obtidos na área do experimento, durante o período de dezembro a abril, no ano agrícola de 2005/2006.

O delineamento experimental utilizado foi de blocos casualizados, com quatro repetições. Os tratamentos foram constituídos por oito cultivares de arroz (BRS Aroma, BRS Bonança, BRS Colosso, BRSMG Conai, BRSMG Curinga, BRS Soberana, BRS Talento e IAC 202), cujas principais características estão na Tabela 1. Cada parcela foi constituída por cinco linhas de 5,0 $\mathrm{m}$ de comprimento. A área útil foi constituída pelas três linhas centrais, desprezando-se 0,50 $\mathrm{m}$ em ambas, as extremidades de cada linha.

O solo foi preparado com uma aração profunda (25$30 \mathrm{~cm}$ ) e três gradagens leves. A aração e a primeira gradagem foram realizadas cerca de 60 dias antes da semeadura. Nessa ocasião foram aplicados $1.200 \mathrm{~kg} \mathrm{ha}^{-1}$ de calcário dolomítico (PRNT $=65 \%$ ), com a finalidade principal de fornecer $\mathrm{Mg}$. A segunda e a terceira gradagens foram realizadas 30 dias antes e às vésperas da semeadura, respectivamente. A adubação básica, calculada de acordo com a análise de solo e as recomendações de Sousa \& Lobato (2004), constou de $300 \mathrm{~kg} \mathrm{ha}^{-1}$ da fórmula N-P-K 8$28-16$ e $20 \mathrm{~kg} \mathrm{ha}^{-1}$ de F.T.E. BR-12 (9,0\% de Zn, $1,8 \%$ de B, $0,8 \%$ de $\mathrm{Cu}, 3,0 \%$ de Fe, $2,0 \%$ de $\mathrm{Mn}$ e $0,1 \%$ de Mo). A abertura dos sulcos e a distribuição dos fertilizantes foram realizadas mecanicamente, no espaçamento de $0,40 \mathrm{~m}$ entrelinhas. A semeadura foi realizada manualmente em 30/ 11/2005, com densidade de 70 sementes viáveis $\mathrm{m}^{-1}$. A emergência das plântulas ocorreu no dia 04/12/2005.

A adubação de cobertura constou da aplicação de $40 \mathrm{~kg} \mathrm{ha}^{-1} \mathrm{de} \mathrm{N}$, na forma de sulfato de amônio, aos 45 dias após a emergência (DAE). O controle de plantas daninhas foi realizado por meio de capinas manuais. Os demais tratos culturais foram os usuais da cultura. 
Tabela 1 - Principais características das cultivares utilizadas no experimento (EMBRAPA, 2007; FORNASIERI FILHO \& FORNASIERI, 2006).

\begin{tabular}{lccccc}
\hline \multicolumn{1}{c}{ Cultivares } & $\begin{array}{c}\text { Floração } \\
(\text { dias })\end{array}$ & $\begin{array}{c}\text { Ciclo } \\
\text { (dias) }\end{array}$ & $\begin{array}{c}\text { Altura da } \\
\text { planta }(\mathrm{m})\end{array}$ & Acamamento & Tipo de grão (classe) \\
\hline BRS Talento & 84 & 110 & $0,85-1,02$ & Resistente & Longo fino \\
BRS Soberana & 79 & 105 & $1,05-1,15$ & Sensível & Longo fino \\
BRSMG Curinga & 97 & 132 & 0,93 & Resistente & Longo fino \\
BRS Aroma & 77 & 110 & 1,07 & Resistente & Longo fino \\
BRS Colosso & 77 & 110 & 0,96 & Resistente & Longo fino \\
BRS Bonança & 88 & 118 & 0,98 & Resistência moderada & Longo \\
BRSMG Conai & 76 & 108 & 0,87 & Resistente & Longo fino \\
IAC 202 & 89 & 120 & 0,87 & Resistente & Longo fino \\
\hline
\end{tabular}

Quando 90\% das panículas apresentavam os grãos com coloração típica de maduros, realizou-se a colheita, manualmente, utilizando-se altura de corte de 15 a $20 \mathrm{~cm}$. Em seguida, foi realizada a secagem à sombra, durante um a dois dias e, posteriormente, a trilha manual.

Foram avaliadas as seguintes características: floração e ciclo, ou seja, o número de dias transcorridos entre a emergência e o florescimento de $50 \%$ das plantas e entre a emergência e a maturação de $90 \%$ das panículas das parcelas; altura das plantas, pela determinação, durante o estádio de grãos na forma pastosa, em dez plantas ao acaso, na área útil de cada parcela, da distância média compreendida desde a superfície do solo até a extremidade da panícula mais alta esticada para cima; número de colmos e de panículas por $\mathrm{m}^{2}$ : determinado mediante a contagem dos colmos e panículas contidos em dois metros de linha, em cada parcela; número de espiguetas/panícula (média de 15 panículas); fertilidade das espiguetas: obtida mediante a relação entre o número de espiguetas cheias e o total de espiguetas por panícula; massa de 1.000 grãos: mediante pesagem de duas amostras de 1.000 grãos de cada parcela; produtividade de grãos: obtida por meio de pesagem dos grãos em casca, proveniente da área útil das parcelas, corrigindo-se a umidade para $13 \%$ e convertendoa em kg ha-1 ${ }^{-1}$ e rendimento de benefício e de grãos inteiros: retirou-se uma amostra de $100 \mathrm{~g}$ de arroz em casca passando-a em engenho de prova Suzuki, modelo MT, por 1 minuto; em seguida foram pesados os grãos brunidos assim obtidos, e o valor encontrado foi considerado como rendimento de benefício, em porcentagem; posteriormente, os grãos brunidos foram colocados no "trieur" $\mathrm{n}^{-} 2$, e a separação dos grãos foi processada por 0,5 minuto; foram pesados os grãos que permaneceram no "trieur", e o valor encontrado foi considerado rendimento de inteiros.

Os dados de cada variável foram submetidos à análise de variância e as médias comparadas pelo teste de Tukey, a 5\% de probabilidade.

Quanto às variáveis fenológicas observadas, ou seja, dias para atingir a floração e ciclo, verificou-se que as cultivares diferiram entre si (Tabela 2). Constatou-se que a cultivar BRSMG Conai floresceu aos 82 DAE e completou seu ciclo aos 106 DAE, confirmando o descrito por Embrapa (2007). Observa-se, ainda, que as cultivares de florescimento mais tardio (BRSMG Curinga, BRS Aroma e IAC 202 com 99, 96 e 96 dias, respectivamente), apresentaram valores contraditórios aos obtidos por Morais et al. (2005), para a cultivar BRSMG Curinga (83 dias), Embrapa (2007), para a cultivar BRS Aroma (77 dias) e Bastos et al. (2000), para a IAC 202 (87 dias). O prolongamento do período para o florescimento e do ciclo da cultura, provavelmente, foi consequiência de veranicos ocorridos durante a fase vegetativa, principalmente na segunda quinzena de janeiro, período pouco antes da diferenciação do primórdio da panícula, especialmente das cultivares mais tardias (Figura 1). A ocorrência de períodos de deficiência hídrica na fase vegetativa da cultura do arroz acaba aumentando o período de sua duração, refletindo em atraso da floração e aumento do ciclo total. Essa discussão é complementada por Crusciol et al. (2003, 2006), Rodrigues et al. (2004) e Stone et al. (1984), que verificaram alteração do período para atingir o florescimento e do ciclo da cultura em função da quantidade de água fornecida à cultura do arroz de terras altas. 
A cultivar BRS Soberana apresentou maior altura de plantas $(1,08 \mathrm{~m})$, característica esta semelhante à descrita pela empresa detentora, 1,05-1,15 m (EMBRAPA, 2007). A cultivar que apresentou menor altura foi a BRS Bonança, com valor $(0,77 \mathrm{~m})$ menor do que os relatados por Lopes \& Silveira Filho (2002) com 1,00 m, porém a altura da planta não diferiu significativamente das cultivares BRS Talento, BRSMG Curinga, BRS Colosso, BRSMG Conai e IAC 202 (Tabela 3). A menor altura de plantas é uma característica interessante para eliminar a possibilidade de acamamento da cultura, fato comum quando a cultura é conduzida sob adequada disponibilidade hídrica e com grandes quantidades de fertilizantes, especialmente os nitrogenados. No presente trabalho não foram observadas plantas acamadas de nenhuma cultivar. A ocorrência de veranico (déficit hídrico) na fase vegetativa da cultura (Figura 1) pode ter contribuído para o menor crescimento das plantas e a não ocorrência de acamamento, conforme relatado por Crusciol et al. $(2003,2006)$ e Rodrigues et al. (2004).

Tabela 2 - Número de dias para floração e ciclo total de cultivares de arroz de terras altas, sob condições de sequeiro em Cassilândia, MS, 2005/06.

\begin{tabular}{lcc}
\hline \multicolumn{1}{c}{ Cultivares } & Floração (dias) & Ciclo (dias) \\
\hline BRS Talento & 94 & 123 \\
BRS Soberana & 87 & 110 \\
BRSMG Curinga & 99 & 123 \\
BRS Aroma & 96 & 123 \\
BRS Colosso & 92 & 110 \\
BRS Bonança & 92 & 110 \\
BRSMG Conai & 82 & 106 \\
IAC 202 & 96 & 120 \\
\hline
\end{tabular}

A cultivar com maior número de colmos e panículas por $\mathrm{m}^{2}$ foi a BRSMG Curinga, com 278,12 e 264,69 por $\mathrm{m}^{2}$, respectivamente, porém diferindo estatisticamente apenas da cultivar BRSMG Conai, para número de colmos e da BRS Colosso, para número de panículas por $\mathrm{m}^{2}$ (Tabela 3 ). A grande diferença no número de colmos por área entre a Cultivar BRSMG Curinga e BRSMG Conai, provavelmente está relacionada com a duração do perfilhamento, que ocorre na fase vegetativa. Assim, a cultivar BRSMG Curinga, por ter floração mais tardia (Tabela 2), produziu mais perfilhos, em comparação à cultivar BRSMG Conai, que foi mais precoce. A intensidade da deficiência hídrica também pode diminuir o perfilhamento, afetando o número de colmos por metro quadrado (FORNASIERI FILHO \& FORNASIERI, 2006), pois leva à dormência as gemas axilares. Com relação ao número de panículas por $\mathrm{m}^{2}$, verifica-se, de maneira geral, que as cultivares que apresentaram maior número de colmos apresentaram também maior número de panículas.

As cultivares apresentaram fertilidade de colmos semelhantes (dados não apresentados), com valor médio de $95 \%$, indicando que os fatores, como espaçamento, densidade de plantas, foram próximos dos ideais para a condição do estudo. Além disso, a boa disponibilidade hídrica (Figura 1) no estádio de diferenciação do primórdio da panícula, provavelmente favoreceu a ocorrência de elevada taxa de fertilidade dos colmos (FORNASIERI FILHO \& FORNASIERI, 2006).

A cultivar IAC 202 apresentou o maior número de espiguetas por panícula, com 187 espiguetas, porém sem diferir estatisticamente da cultivar BRS Colosso (Tabela 3). Buzetti et al. (2006), também obtiveram valores semelhantes nessa cultivar, com 191 espiguetas. A cultivar BRSMG Conai apresentou o menor número de espiguetas por panícula $(93,2)$, ou seja, cerca de metade da cultivar IAC 202, porém, não diferindo significativamente para a maioria das cultivares. O menor número de espiguetas por panícula da cultivar BRSMG Conai pode estar associado ao seu florescimento precoce e à deficiência hídrica ocorrida durante o início da sua fase reprodutiva (Tabela 2 e Figura 1). De acordo com Yoshida (1981), o número total de espiguetas é influenciado por fatores genéticos e condições externas vigentes durante a fase reprodutiva, mais precisamente do início da fase reprodutiva até cinco dias que antecedem o florescimento.

Não houve diferença entre as cultivares no que se refere à fertilidade das espiguetas (Tabela 3), sendo que, de modo geral, todas as cultivares apresentaram elevado valor dessa variável (acima de 76\%), o que foi decorrente da boa disponibilidade hídrica ocorrida nos dias próximos ao florescimento (Figura 1). Várias condições adversas que ocorrem durante o desenvolvimento da meiose da célula-mãe do grão de pólen e no florescimento, ou seja, 10 dias antes e após o início do florescimento, podem influenciar a porcentagem de espiguetas granadas. Entre as condições climáticas desfavoráveis, constam as altas e baixas temperaturas do ar, baixa radiação solar, deficiência hídrica e ventos fortes (YOSHIDA \& PARAO, 1976). 


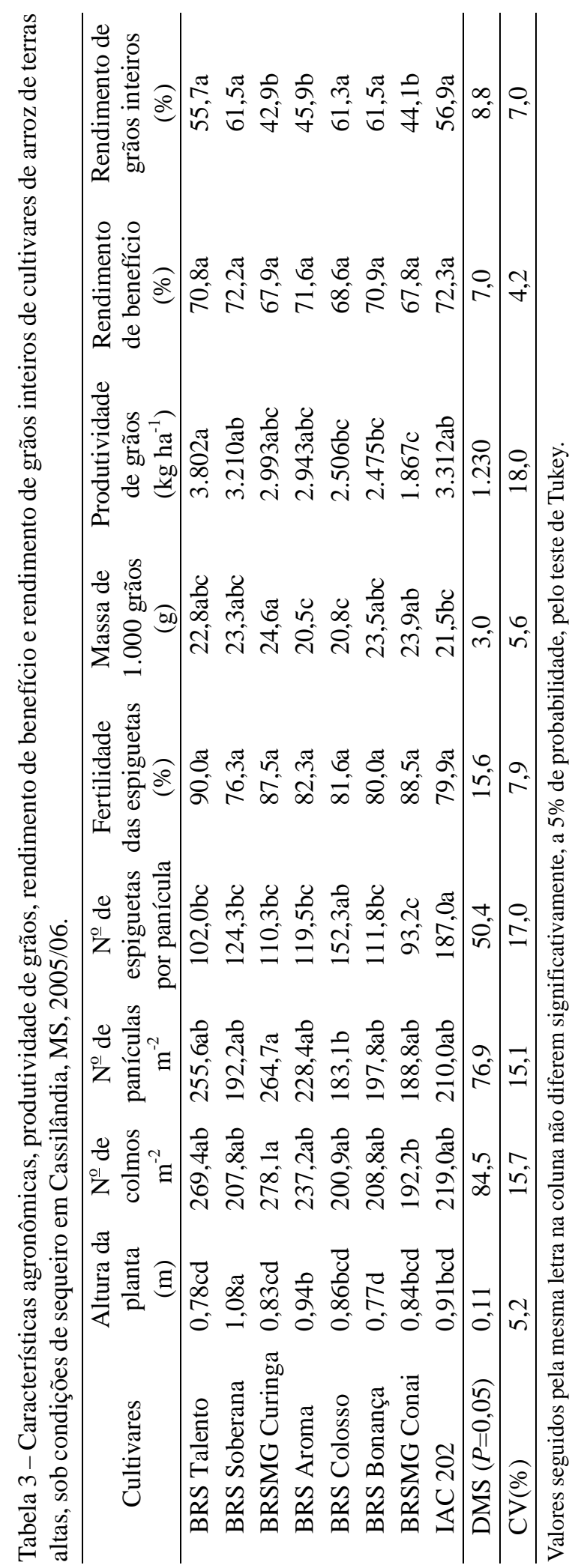

Para a massa de 1.000 grãos, nota-se que a cultivar BRSMG Curinga apresentou a maior média, semelhante ao obtido por Morais et al. (2005), porém, diferindo apenas dos cultivares BRS Aroma, BRS Colosso e IAC 202 (Tabela 3). Para as cultivares BRS Colosso e BRS Aroma, que obtiveram as menores médias (20,8 e 20,5 g), são valores semelhantes ao obtidos por Lopes et al. (2004) com 22,3 g para a cultivar BRS Colosso e pela Embrapa (2007) com 21,5 g para a cultivar BRS Aroma, o que demonstra uma boa massa de grãos para todas as cultivares estudadas, indicando que as condições do estudo não limitaram o desenvolvimento e enchimento dos grãos.

Com relação à produtividade de grãos (Tabela 3), destacou-se a cultivar BRS Talento, alcançando uma produtividade média de $3.802 \mathrm{~kg} \mathrm{ha}^{-1}$, o que corresponde a 63,3 sacas de $60 \mathrm{~kg}$ de arroz em casca, produtividade superior à obtida por Morais et al. (2004), porém, não diferindo significativamente das cultivares BRS Soberana, BRSMG Curinga, BRS Aroma e IAC 202. A cultivar BRSMG Conai foi a que apresentou a menor produtividade 1.867 $\mathrm{kg} \mathrm{ha}^{-1}$, resultado este $41,5 \%$ inferior ao alcançado por Reis et al. (2006), experimento este conduzido em Minas Gerais. A menor produtividade da cultivar BRSMG Conai, provavelmente está associada ao início de sua fase reprodutiva, em época de ocorrência de veranico (janeiro), o que reduziu o número de panículas por $\mathrm{m}^{2} \mathrm{e}$ principalmente o número de espiguetas por panícula, refletindo em menor produtividade.

Quanto ao rendimento de benefício, verifica-se que não houve diferença estatística entre as cultivares (Tabela 3), sendo os valores semelhantes aos observados por Crusciol et al. (1999c) e Rodrigues et al. (2004), respectivamente para as cultivares IAC 201, Maravilha e Confiança, também em condições de sequeiro.

Quanto ao rendimento de grãos inteiros, verificase que as cultivares BRS Soberana, BRS Bonança, BRS Colosso, BRS Talento e IAC 202 se destacaram das demais apresentando rendimento de inteiros superior a 55\%, valor maior que o observado por Arf et al. (2002), e Crusciol et al. (1999c) em condição de sequeiro.

Considerando o conjunto de características de interesse, as cultivares BRS Talento, IAC 202 e BRS Soberana são as mais indicadas para a região do município de Cassilândia, MS, sendo possível obterse boa produtividade (acima de $3.000 \mathrm{~kg} \mathrm{ha}^{-1}$ ), na cultura do arroz de terras altas sob condições de sequeiro nessa região, desde que sejam utilizadas cultivares adequadas. 


\section{AGRADECIMENTOS}

Ao Dr. Orlando Peixoto de Morais, pesquisador da Embrapa Arroz e Feijão, pela doação das sementes utilizadas no experimento e ao Prof. Dr. Orivaldo Arf, da Faculdade de Engenharia da UNESP, campus de Ilha Solteira, pelas avaliações de qualidade de grãos.

\section{REFERÊNCIAS BIBLIOGRÁFICAS}

ARF, O.; RODRIGUES, R. A. F.; SÁ, M. E. de; CRUSCIOL, C. A. C.; PEREIRA, J. C. dos R. Preparo do solo, irrigação por aspersão e rendimento de engenho do arroz de terras altas. Scientia Agricola, Piracicaba, v. 59, n. 2, p. 321-356, 2002.

BASTOS, C. R. do; TISSELLI FILHO, O.; AZZINI, L. E.; MARTINS, A. L. M.; PETTINELLI FILHO, A.; PAULO, M. P.; SOAVE, J.; PEREIRA, J. C. V. N. A.; CASTRO, L. H. S. M. de; RAZERA, L. F.; CARVALHO, L. H.; BORTOLETTO, N.; GALLO, P. B. IAC 202: arroz de alta produtividade e qualidade para cultura de sequeiro. Campinas: $\mathrm{O}$ Agronômico, 2000. 2 p. (Comunicado técnico, 52/1).

BRESEGHELLO, F.; CASTRO, E. da M. de; MORAIS, O. P. de. Cultivares de arroz. In: BRESEGHELLO, F.; STONE, L. F. (Eds.). Tecnologia para o arroz de terras altas. Santo Antonio de Goiás: Embrapa Arroz e Feijão, 1998. p. 41-53.

BUZETTI, S.; BAZANINI, G. C.; FREITAS, J. G. de; ANDREOTTI, M.; ARF, O.; SÁ, M. E.; MEIRA, F. de A. Resposta de cultivares de arroz a doses de nitrogênio e do regulador de crescimento cloreto de clormequat. Pesquisa Agropecuária Brasileira, Brasília, v. 41, n. 12, p. 1731-1737, 2006.

CASTRO, E. da M. de; BRESEGHELLO, F.; MORAIS, O. P. de. Cultivares. In: KLUTHCOUSKI, J.; PINHEIRO, B. da S. (Eds.). Cultivo de arroz de terras altas. Disponível em: 4http://sistemasdeproducao.cnptia.embrapa.bry. Acesso em: 25 abr. 2007.

CRUSCIOL, C. A. C.; ARF, O.; SORATTO, R. P.; RODRIGUES, R. A. F.; MACHADO, J. R. Manejo de irrigação por aspersão com base no "Kc" e adubação mineral na cultura de arroz de terras altas. Bragantia, Campinas, v. 62, n. 3, p. 465-75, 2003.

CRUSCIOL, C. A. C.; MACHADO, J. R.; ARF, O.; RODRIGUES, R. A. F. Componentes de produção e produtividade de grãos de arroz de sequeiro em função do espaçamento e da densidade de semeadura. Scientia Agricola, Piracicaba, v. 56, n. 1, p. 53-62, 1999a.
CRUSCIOL, C. A. C.; MACHADO, J. R.; ARF, O.; RODRIGUES, R. A. F. Matéria seca e absorção de nutrientes em função do espaçamento e da densidade de semeadura em arroz de terra alta. Scientia Agricola, Piracicaba, v. 56, n. 1 , p. 63-70, 1999 b.

CRUSCIOL, C. A. C.; MACHADO, J. R.; ARF, O.; RODRIGUES, R. A. F. Rendimento de benefício e de grãos inteiros em função do espaçamento e da densidade de semeadura do arroz de sequeiro. Scientia Agricola, Piracicaba, v. 56, n. 1, p. 47-52, 1999c.

CRUSCIOL, C. A. C.; SORATTO, R. P.; ARF, O.; MATEUS, G. P. Yield of upland rice cultivars in rainfed and sprinklerirrigated systems in the Cerrado region of Brazil. Australian Journal of Experimental Agriculture, Collingwood, v. 46, n. 9, p. 1515-1520, 2006.

EMPRESA BRASILEIRA DE PESQUISA AGROPECUÁRIA. Centro Nacional de Pesquisa de Solos (Rio de Janeiro, RJ). Sistema brasileiro de classificação dos solos. Brasília, DF: Embrapa-SPI; Embrapa-CNPS, 1999. 412 p.

EMPRESA BRASILEIRA DE PESQUISA AGROPECUÁRIA. Empresa Arroz e Feijão. Cultivares de arroz. Disponível em: 〈http://www.cnpaf.embrapa.br/arroz/index.htmp. Acesso em: 28 jun. 2007.

FORNASIERI FILHO, D.; FORNASIERI, J. L. Manual da cultura do arroz. Jaboticabal: Funep, 2006. 589 p.

LOPES, A. de M.; SILVEIRA FILHO, A. BRS Bonança: cultivar de arroz de Sequeiro recomendada para a região Nordeste do Estado do Pará. Belém: Embrapa Amazônia Oriental, 2002. 4 p. (Comunicado técnico, 72).

LOPES, A. de M.; SILVEIRA FILHO, A.; CORREA, J. R. V. BRS Colosso: cultivar de arroz de terra firme para o agronegócio no Estado do Pará. Belém: Embrapa Amazônia Oriental, 2004. 3 p. (Comunicado técnico, 101).

MORAIS, O. P. de; CASTRO, E. da M. de; SOARES, A. A.; GUIMARÃES, É. P.; CHATEL, M.; OSPINA, Y.; LOPES, A. de M.; PEREIRA, J. de A.; UTUMI, M. M.; CENTENO, A. C.; FONSECA, J. R.; BRESEGHELLO, F.; GUIMARÃES, C. M.; BASSINELLO, P. Z.; PRABHU, A. P.; FERREIRA, E.; SOUZA, N. G. de; SOUZA, M. A. de; REIS, M. de S.; SANTOS, P. G. BRSMG Curinga: cultivar de arroz de terras altas de ampla adaptação para o Brasil. Santo Antônio de Goiás: Embrapa Arroz e Feijão, 2005. 8 p. (Comunicado técnico, 114). 
MORAIS, O. P. de; CASTRO, E. M. de; SOUZA, N. R. G. de; PRABHU, A. S.; BASSINELLO, P. Z.; FONSECA, J. R. Cultivares de arroz de terras altas para o Mato Grosso. Santo Antonio de Goiás: Embrapa Arroz e Feijão, 2004. 8 p. (Circular técnica, 68).

RANGEL, P. H. N.; PEREIRA, J. A.; MORAIS, O. P. de; GUIMARÃES, E. P.; YOKOKURA, T. Ganhos na produtividade de grãos pelo melhoramento genético do arroz irrigado no meio-norte do Brasil. Pesquisa Agropecuária Brasileira, Brasília, v. 35, n. 8, p. 1595-1604, 2000.

REIS, M. de S.; SOARES, A. A.; CORNÉLIO, V. M. de O.; SOARES, P. C.; GUEDES, J. M. Cultivares e linhagens de arroz de terras altas avaliadas sob sistema plantio direto e convencional. In: REUNIÃO NACIONAL DE PESQUISA DE ARROZ, 8., 2006, Brasília, DF. Anais... Santo Antonio de Goiás: Embrapa Arroz e Feijão, 2006. CD-ROM.

RODRIGUES, R. A. F.; SORATTO, R. P.; ARF, O. Manejo de água em arroz de terras altas no sistema de plantio direto, usando o Tanque Classe A. Engenharia Agrícola, Jaboticabal, v. 24, n. 3, p. 546-556, 2004.

SOUSA, D. M. G. de; LOBATO, E. Cerrado: correção do solo e adubação. Brasília, DF: Embrapa Informação Tecnológica, 2004. 416 p

STONE, L. F.; LIBARDI, P. L.; REICHARDT, K. Deficiência hídrica, vermiculita e cultivares. Pesquisa Agropecuária Brasileira, Brasília, v. 19, n. 7, p. 695-707, 1984.

STONE, L. F.; MOREIRA, J. A. A.; RABELO, R. R.; BIAVA, M. Arroz: o produtor pergunta a Embrapa responde. Brasília, DF: Embrapa Arroz e Feijão; Embrapa Informação Tecnológica, 2001. 232 p.

YOSHIDA, S. Climatic environmentand its influence. In: Fundamentals of rice crop science. Los Baños: International Rice Research Institute, 1981. cap. 2, p. 65-110.

YOSHIDA, S.; PARAO, F. T. Climatic influence on yield and yield components of lowland rice in the tropics. In: INTERNATIONAL RICE RESEARCH INSTITUTE, 1976, Los Baños. Proceedings... Los Baños: [s.n.], 1976. p. 471-491. 